\title{
Redox-neutral Photocatalytic C-H Carboxylation of Arenes and Styrenes with $\mathrm{CO}_{2}$
}

\author{
Matthias Schmalzbauer, ${ }^{1,5}$ Thomas D. Svejstrup, ${ }^{2,5}$ Florian Fricke, ${ }^{1}$ Peter Brandt, ${ }^{2}$ Magnus J. Johansson, ${ }^{2,3}$ \\ Giulia Bergonzini, ${ }^{2, *}$ and Burkhard König ${ }^{1,4, * *}$ \\ ${ }^{1}$ Faculty of Chemistry and Pharmacy, University of Regensburg, Germany \\ ${ }^{2}$ Medicinal Chemistry, Research and Early Development Cardiovascular, Renal and Metabolism, BioPharmaceuticals R\&D, AstraZeneca, Gothenburg, Sweden \\ ${ }^{3}$ Department of Organic Chemistry, Stockholm University, Stockholm 10691, Sweden \\ ${ }^{4}$ Lead Contact \\ ${ }^{5}$ These authors contributed equally \\ *Correspondence: giulia.bergonzini@astrazeneca.com \\ **Correspondence: burkhard.koenig@ur.de
}

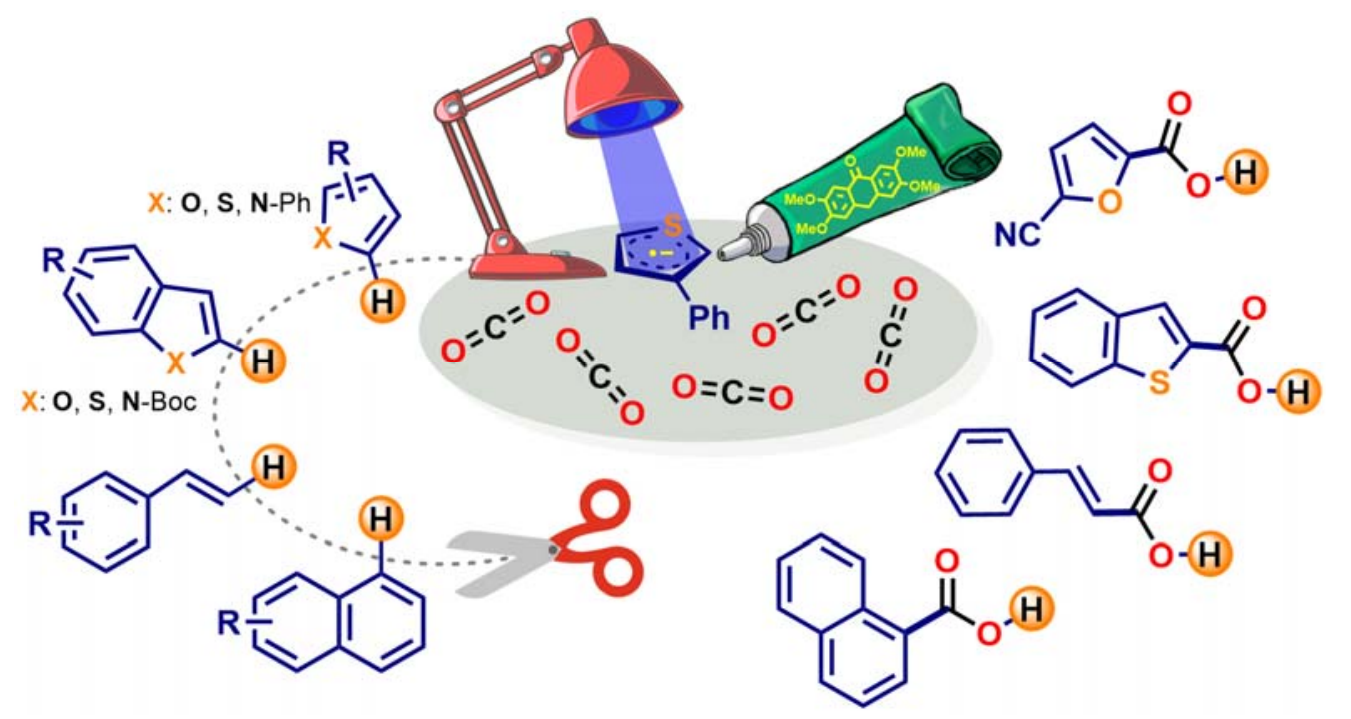

\begin{abstract}
Carbon dioxide $\left(\mathrm{CO}_{2}\right)$ is an attractive one-carbon $(\mathrm{C} 1)$ building block in terms of sustainability and abundance. However, its low reactivity limits applications in organic synthesis as typically high-energy reagents are required to drive transformations. Here, we present a redox-neutral $\mathrm{C}-\mathrm{H}$ carboxylation of arenes and styrenes using a photocatalytic approach. Upon blue-light excitation, the anthrolate anion photocatalyst is able to reduce many aromatic compounds to their corresponding radical anions, which react with $\mathrm{CO}_{2}$ to afford carboxylic acids. High-throughput screening and computational analysis suggest that a correct balance between electron affinity and nucleophilicity of substrates is essential. This novel methodology enables the carboxylation of numerous aromatic compounds, including many that are not tolerated in classical carboxylation chemistry. Over 50 examples of $\mathrm{C}-\mathrm{H}$ functionalizations using $\mathrm{CO}_{2}$ or ketones illustrate a broad applicability. The method opens new opportunities for late-stage $\mathrm{C}-\mathrm{H}$ carboxylation and valorization of common arenes.
\end{abstract}

Keywords: Photocatalysis, carbon dioxide, carboxylation, $\mathrm{C}-\mathrm{H}$ functionalization, radical anion, carboxylic acid, 9-anthrone, styrene, heteroarenes 


\section{INTRODUCTION}

Photosynthesis, the most important photobiological process on our planet, allows photoautotrophs to store energy in form of chemical bonds by absorbing sunlight. Driven by that energy, $\mathrm{CO}_{2}$ is captured from the atmosphere and serves as carbon feedstock for the organisms to build up sugars and biomass in the Calvin cycle. ${ }^{1}$

Electrochemical and catalytic dihydrogen reductions of carbon dioxide have been developed in the field of renewable energy storage. ${ }^{2-4}$ However, the use of $\mathrm{CO}_{2}$ as a $\mathrm{C} 1$ building block in organic synthesis has received far less attention despite resembling the principle of biological carbon fixing process the most. ${ }^{5}$ The high thermodynamic stability and kinetic inertness of $\mathrm{CO}_{2}$ require the use of stoichiometric amounts of reactive reaction partners such as Grignard reagents or organolithium compounds for chemical conversion. ${ }^{6}$ Aiming for a better efficiency and an increased atom economy, a variety of catalytic carboxylation methods have been developed. These processes make use of readily available aryl bromides which undergo carboxylation with $\mathrm{CO}_{2}$ in the presence of catalytic $\mathrm{Pd}(\mathrm{OAc})_{2}$, as reported by Martín and Correa. ${ }^{7}$ Daugulis showed that $\mathrm{Cu}(\mathrm{I})$ catalyzes the carboxylation of aryl iodides. ${ }^{8}$ Tsuji and co-workers applied $\mathrm{NiCl}_{2}\left(\mathrm{PPh}_{3}\right)_{2}$ to carboxylate more inert aryl and vinyl chlorides under $1 \mathrm{~atm} \mathrm{CO}_{2}$ at room temperature. ${ }^{9}$ The reaction scope was extended to sulfonates, ${ }^{10}$ ester derivatives, ${ }^{11,12}$ allylic alcohols, ${ }^{13}$ benzylic ammonium salts, ${ }^{14}$ arylsulfonium salts ${ }^{15}$ and unsaturated hydrocarbons. ${ }^{16-20}$ However, all these systems require stoichiometric reducing reagents based on $\mathrm{Et}_{2} \mathrm{Zn}, \mathrm{AlMe}_{3}$, $\mathrm{Mn}$ and $\mathrm{Zn}$ powder or prefunctionalized starting materials. ${ }^{21}$ Electrical current may also be used to drive reductive carboxylation chemistry. Buckley and co-workers reported the regioselective hydrocarboxylation of styrenes using a non-sacrificial electrode system. ${ }^{22}$ Ackermann et al. showed that allyl chlorides derived from cinnamyl chloride are carboxylated in presence of a cobalt catalyst. ${ }^{23}$ Concomitantly, difunctionalizations of alkenes via radical addition and subsequent reduction were reported affording thio-, ${ }^{24}$ carbo- ${ }^{25-27}$ phosphono- ${ }^{28}$ or silylcarboxylation ${ }^{27}$ products.

Non-catalytic $\mathrm{C}\left(\mathrm{sp}^{2}\right)-\mathrm{H}$ carboxylations typically require stoichiometric amounts of either strong bases, such as $\mathrm{NaH}^{29}$ or $\mathrm{LiO}^{t} \mathrm{Bu},{ }^{30,31}$ or Lewis acids, like $\mathrm{AlX}_{3}(\mathrm{X}=\mathrm{Br}, \mathrm{Cl}),{ }^{32-35} \mathrm{Me}_{2} \mathrm{AlCl}^{36}$ and $\mathrm{EtAlCl}_{2}{ }^{37,38}$ to activate $\mathrm{CO}_{2}$. Transition metal-catalyzed directed $\mathrm{C}\left(\mathrm{sp}^{2}\right)-\mathrm{H}$ carboxylation reactions have been reported with $\mathrm{Au}^{39} \mathrm{Cu}^{39,40}$ and $\mathrm{Rh}^{41}$ complexes. ${ }^{42}$ Moreover, direct carboxylation of non-activated $\mathrm{C}\left(\mathrm{sp}^{2}\right)-\mathrm{H}$ was reported in molten alkali carbonate salts under elevated temperatures $\left(>200{ }^{\circ} \mathrm{C}\right)$ and high $\mathrm{CO}_{2}$ pressure..$^{43,44}$

More recently, photoredox catalysis has been applied in the field of carboxylation chemistry. Photocatalytic carboxylation of aryl- $-^{45,46}$ and alkyl-halides ${ }^{46}$ were the first transformations to be reported, followed by direct $\mathrm{C}-\mathrm{H}$ carboxylation of alkynes ${ }^{47}$ and styrenes. ${ }^{48,49}$ These methods utilize a dual catalytic approach consisting of a photocatalyst and an in situ generated low-valent transition metal complex enabled by an excess amount of a sacrificial electron donor. Visible-light mediated benzylic $\mathrm{C}-\mathrm{H}$ carboxylation was recently reported by the use of $4 \mathrm{CzIPN}$ and an organo-silanethiol HAT reagent which allowed to generate carbanions. ${ }^{50}$ 
Direct UV-light excitation of polyaromatic hydrocarbons in presence of sacrificial amines and $\mathrm{CO}_{2}$ was reported to yield the corresponding carboxylic acids. ${ }^{51,52}$ Jamison employed $p$-terphenyl, which forms a radical anion upon UV-light excitation in the presence of amines. ${ }^{53}$ The $p$-terphenyl radical anion is capable of the kinetically slow one-electron reduction of $\mathrm{CO}_{2}$ to its radical anion, which is used in the hydrocarboxylation of styrenes (see Scheme 1). Murakami and co-workers employed UV-excited xanthone as hydrogen-atom-transfer (HAT) reagent in combination with a $\mathrm{Cu}$ complex or a Ni catalyst to carboxylate allylic ${ }^{54}$ and benzylic ${ }^{55} \mathrm{C}\left(\mathrm{sp}^{3}\right)-\mathrm{H}$ respectively.

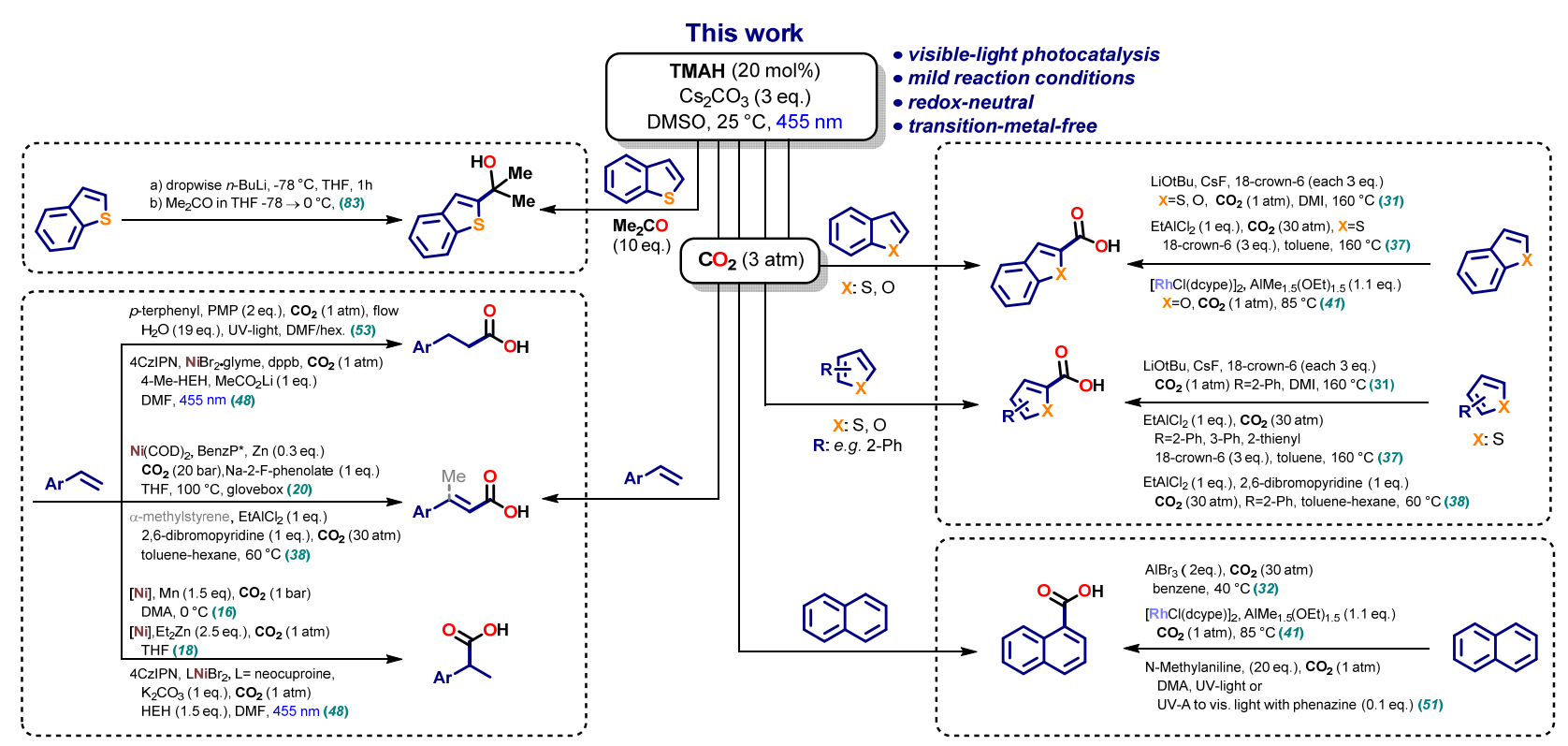

Scheme 1. Overview of representative literature procedures for the direct $\mathrm{C}-\mathrm{H}$ carboxylation with $\mathrm{CO}_{2}$ or hydroxyalkylation with acetone considering the herein discussed substrate classes.

However, despite the great progress achieved in thermal and photochemical carboxylation methods, the efficient redox-neutral carboxylation of $\mathrm{C}\left(\mathrm{sp}^{2}\right)-\mathrm{H}$ in arenes, heteroarenes and alkenes remains challenging. Here, we report a mechanistically different catalytic approach in which aromatic compounds are converted into their radical anions by photoinduced single-electron transfer (SET) from a visible-light excited anthrolate anion. The generated nucleophilic arene radical anions react with $\mathrm{CO}_{2}$ to provide (hetero)aromatic carboxylic- and cinnamic acids.

\section{RESULTS \& DISCUSSION}

Recently, we showed that upon photoexcitation, the anionic form of commercially available 9-anthrone and derivatives (Scheme 2 and Figure S6, Supplemental Information) readily generate strong reductants capable of activating aryl chlorides. ${ }^{56}$ While comparing reported reduction potentials of various aromatic compounds, we noticed that many arenes lay within the range of the approximated excited state oxidation potential of the strongest 
photo-reductant 2,3,6,7-tetramethoxyanthracen-9(10H)-one (TMAH) $\left[E_{\text {ox }}\left(\right.\right.$ TMA $^{*} /$ TMA $\left.^{-*}\right)=-2.92 \mathrm{~V}$ vs. SCE] shown in that series. We thus envisioned a direct activation of arenes via radical anion formation, which may subsequently react with $\mathrm{CO}_{2}$ to form aromatic carboxylic acids. Strong carbon nucleophiles (e.g. organolithium and -magnesium reagents) ${ }^{57-60}$ or carbanions are well known to react with $\mathrm{CO}_{2}$. By contrast, aromatic radical anions formed in the presence of alkali metal have always been considered poor nucleophiles, ${ }^{61}$ yet still showed reactivity towards $\mathrm{CO}_{2}{ }^{62,63}$ With a strongly reducing photoredox catalyst in hand and inspired by early literature reports, we questioned if a similar reactivity of aromatic radical anions towards carbon dioxide can be obtained under much milder photocatalytic conditions.
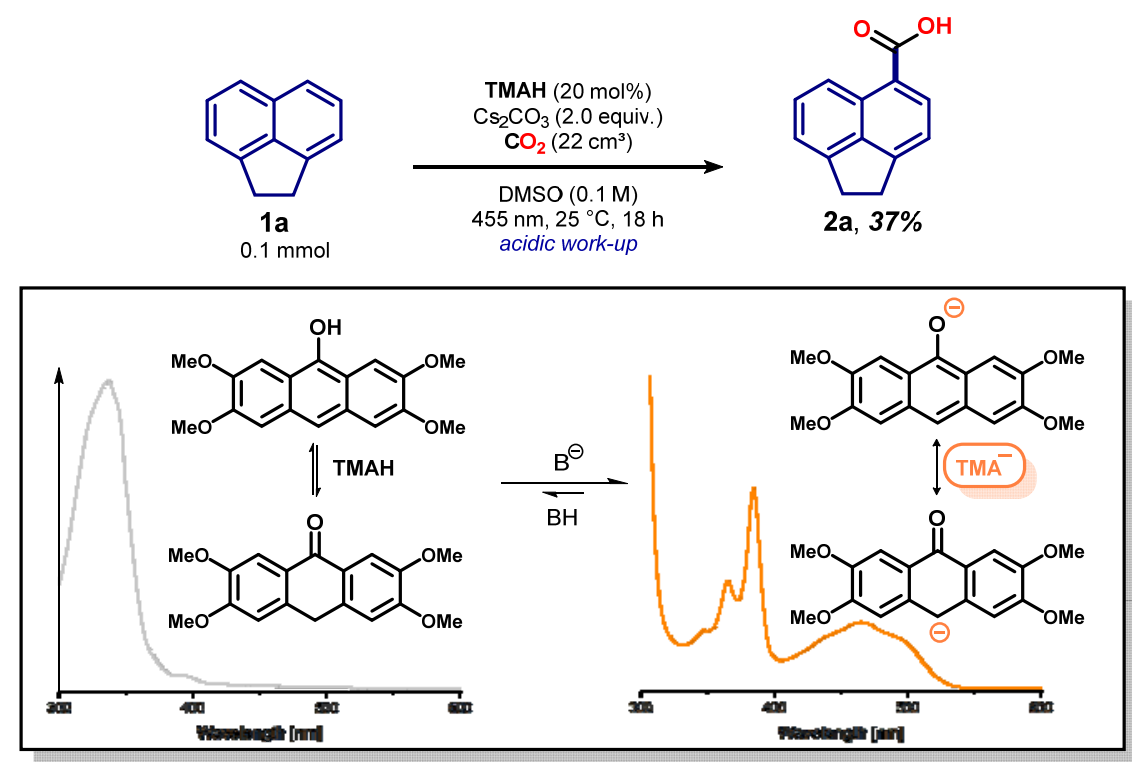

Scheme 2. (top) Photocatalytic $\mathrm{C}-\mathrm{H}$ carboxylation of acenaphthene 1a; (bottom) Basepromoted formation of $\mathrm{TMA}^{-}$and the influence on the absorption spectrum.

\section{Initial experiments and optimization}

We chose acenaphthene (1a, Scheme 2) as a model substrate and applied the established combination of TMAH as the photocatalyst and cesium carbonate as the base. To our delight, after 18 hours of irradiation with blue LED light and acidic work-up, the desired carboxylic acid 2a could be isolated in 37\% yield as a single regioisomer. Encouraged by this first result we run an intensive screening of the reaction conditions (Table 1). During the optimization studies, we observed that the reaction outcome was dependent on the amount of $\mathrm{Cs}_{2} \mathrm{CO}_{3}$. The use of less than 3 equivalents of base led to significantly lower product yield (entry 2) while more equivalents of $\mathrm{Cs}_{2} \mathrm{CO}_{3}$ reduced the yield (entry 3). A lower catalyst loading reduced the overall amount of base required, while the carboxylated product 2a was still obtained in good yield (entry 4-5). $\mathrm{K}_{2} \mathrm{CO}_{3}$, although being scarcely soluble in DMSO, was also able to promote the carboxylation reaction and useful product yields were obtained in combination with crown-ether (entry 6). Monitoring the reaction progress over time (Figure S8, Supplemental 
Information) showed that the reaction was not complete after 6 hours (entry 7). An overpressure of $\mathrm{CO}_{2}$ was found to be beneficial for the reaction outcome (entries 8 and 9). The solubility of $\mathrm{CO}_{2}$ is reported to be higher in DMF compared to DMSO, yet better yield was obtained in the latter (entry 10). ${ }^{64}$ When using green light (535 nm), a reduced product yield was obtained (entry 11), which can be explained by both weaker catalyst absorption and LED radiant flux. Control experiments revealed that all reagents and light are crucial, as no product was detected in the absence of either photocatalyst, cesium carbonate, carbon dioxide or light (entry 12-15).

Table 1. Optimized reaction conditions and effects upon deviation.

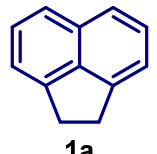

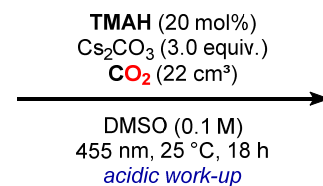

acidic work-up

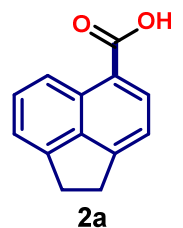

2a

\begin{tabular}{|c|c|c|}
\hline Entry & Deviations from optimized conditions & Yield 2a $[\%]^{\mathrm{a}}$ \\
\hline 1 & none & $68^{\mathrm{b}}$ \\
\hline 2 & $\mathrm{Cs}_{2} \mathrm{CO}_{3}$ (2 equiv.) & $37^{\mathrm{b}}$ \\
\hline 3 & $\mathrm{Cs}_{2} \mathrm{CO}_{3}$ (4 equiv.) & 59 \\
\hline 4 & TMAH (5 mol\%), $\mathrm{Cs}_{2} \mathrm{CO}_{3}$ (2 equiv.) & 54 \\
\hline 5 & TMAH (10 mol\%), $\mathrm{Cs}_{2} \mathrm{CO}_{3}$ (2 equiv.) & 60 \\
\hline $6^{\mathrm{c}}$ & TMAH (10 mol\%), $\mathrm{K}_{2} \mathrm{CO}_{3}$ instead of $\mathrm{Cs}_{2} \mathrm{CO}_{3}, 18$-crown-6 & 47 \\
\hline 7 & 6 hours instead of 18 hours & 44 \\
\hline 8 & no $\mathrm{CO}_{2}$ pressure $(1 \mathrm{~atm})$ & 37 \\
\hline 9 & $11 \mathrm{~cm}^{3} \mathrm{CO}_{2}$ instead of $22 \mathrm{~cm}^{3}$ & 48 \\
\hline 10 & DMF instead of DMSO & 35 \\
\hline $11^{\mathrm{d}}$ & $535 \mathrm{~nm}$ instead of $455 \mathrm{~nm}$ & 29 \\
\hline 12 & no ТМАН & n.d. \\
\hline 13 & no $\mathrm{Cs}_{2} \mathrm{CO}_{3}$ & n.d. \\
\hline 14 & $\mathrm{~N}_{2}(1 \mathrm{~atm})$ instead of $\mathrm{CO}_{2}$ & n.d. \\
\hline $15^{\mathrm{e}}$ & no light & n.d. \\
\hline
\end{tabular}

Optimized reaction conditions: $1 \mathbf{a}(0.1 \mathrm{mmol})$, TMAH $(20 \mathrm{~mol} \%)$ and $\mathrm{Cs}_{2} \mathrm{CO}_{3}(0.3 \mathrm{mmol})$ were added to a $5 \mathrm{~mL}$ crimp top vial equipped with a stirring bar. The vial was sealed, evacuated and backfilled with $\mathrm{CO}_{2}(5 \times)$. Degassed, anhydrous DMSO $(1 \mathrm{~mL})$ was added via syringe. The septum was further sealed with Parafilm ${ }^{\circledR}$ and gaseous $\mathrm{CO}_{2}\left(22 \mathrm{~cm}^{3}\right)$ was added to the headspace via syringe. While stirring, the reaction was irradiated from the bottom side (blue LED, $455 \pm 15 \mathrm{~nm}$ ) and constant temperature was maintained by an aluminum cooling block and a water-cooling circuit. For complete optimization table, please see Table S1, Supplemental Information. n.d. $=$ not detected. ${ }^{\text {a }}$ Product yield was determined after acidic work-up by crude ${ }^{1} \mathrm{H}-\mathrm{NMR}$ with an internal standard. ${ }^{b}$ Combined isolated yield of four reactions. ${ }^{c}$ Crown ether 18 -crown-6 (1 equiv.) was added to the reaction. ${ }^{\mathrm{d}}$ Radiant flux is lowered by a factor of 8 compared to $455 \mathrm{~nm}$ LED (see Supplemental Information). ${ }^{\mathrm{e}}$ Reaction mixture was stirred in the dark. 


\section{Substrate scope of the carboxylation reaction}

With the optimized reaction conditions in hand (cf., Table 1), we explored the scope of this novel transformation. Naphthalene derivatives were investigated, as their reported potentials are in a feasible range $(-2.49$ up to $-2.65 \mathrm{~V}$ vs. $\mathrm{SCE})^{65}$ for reduction by the photocatalyst (Scheme 3). We were pleased to see that unsubstituted as well as substituted naphthalene derivatives were converted to the corresponding aromatic carboxylic acids (2b-g) and could be isolated in useful yields. The regioselectivity of the reaction was found to be affected by strong electrondonating groups (-OMe 2c, $-\mathrm{NMe}_{2} \mathbf{2 d}$ ) in the C1-position giving selectively 5-naphtoic acids as single regioisomers. In contrast, the directing effect of electronically neutral substituents (-Me, 2e) was minor and led to a mixture of 4- and 5-naphtoic acid. Remarkably, carboxylation in the C8-position was not observed. Notably, unprotected hydroxyl groups (2f, 2g) were tolerated. Utilizing 1-naphthol (1f) led to the formation of two regioisomers of the corresponding acid in 2- and 4-position. 2,7-Dihydroxynaphthalene (1g) reacted smoothly under our reaction conditions to yield the corresponding 1-naphtoic acid $\mathbf{2 g}$ as a single regioisomer. Quinoline (1h), isoquinoline or quinazoline, although quenching the photoexcited state of the catalyst, failed to yield any product.

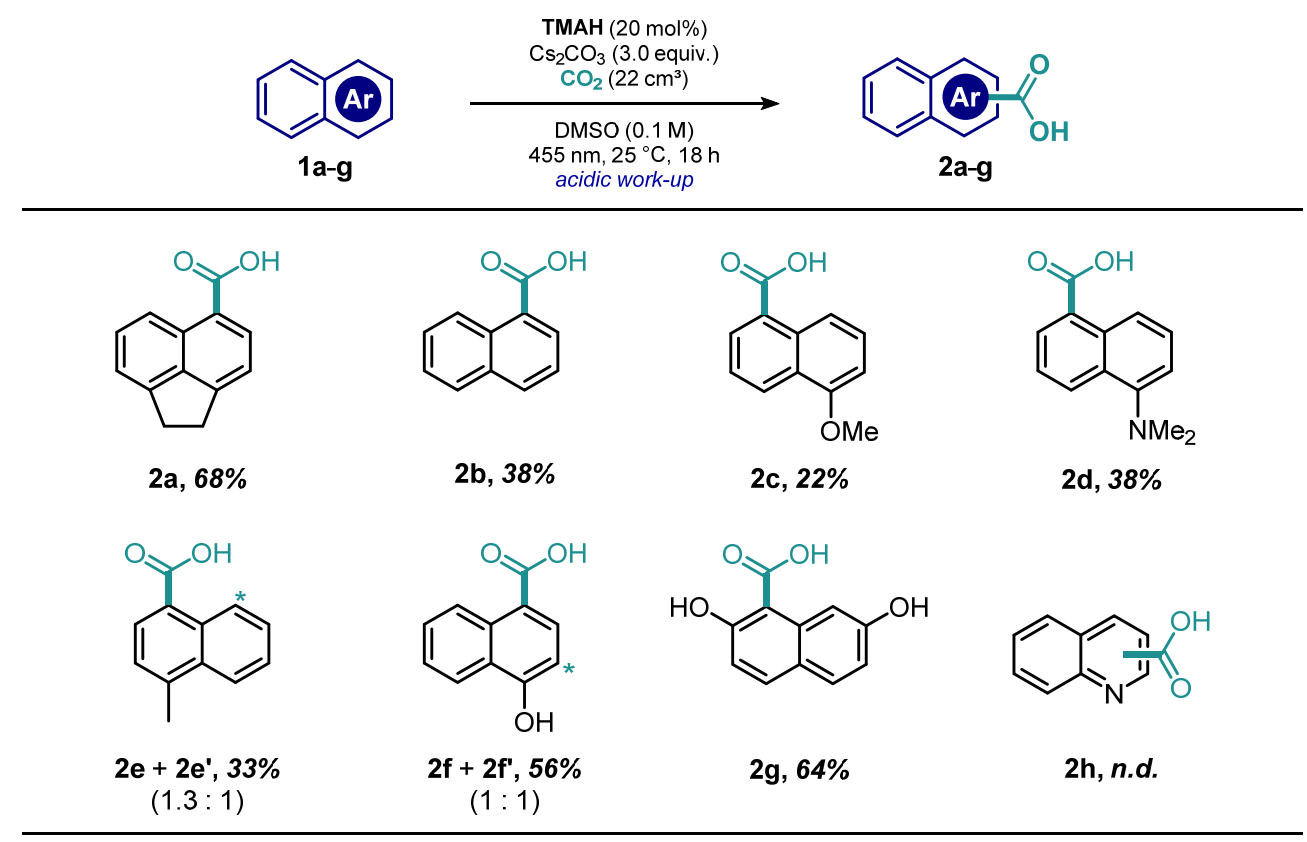

Scheme 3. Substrate scope for the carboxylation of naphthalene derivatives.

Pleasingly, many other heteroaromatic compounds were suitable substrates for our carboxylation method (Scheme 4). Thiophenes, bearing electron-deficient (3a-d, 3f, 3i-k) and -neutral (3e, 3g-h, 3I-n) substituents smoothly converted into the corresponding thiophenecarboxylic acids 4a-n in good to excellent yield. Remarkably, a broad range of functional groups including ketones, esters, amides, $-\mathrm{CH}_{2} \mathrm{CO}_{2} \mathrm{Me},-\mathrm{CH}_{2} \mathrm{CN}$, phenyl-, trimethylsilyl-, 
nitrile were tolerated. However, unfunctionalized thiophene could not be activated by the photocatalyst (see Figure S11b, Supplemental Information). Due to the mild nature of this reaction, we were pleased to see that regioselectivity was maintained even with substrates containing acidic $\mathrm{C}-\mathrm{H}(\mathbf{4} \mathbf{c}, \mathbf{4 j})$ or active methylene groups (4g-h). This is in contrast to reported base promoted methods that are usually selective for the most acidic position of the substrates and that fail in the presence of sensitive functionalities.

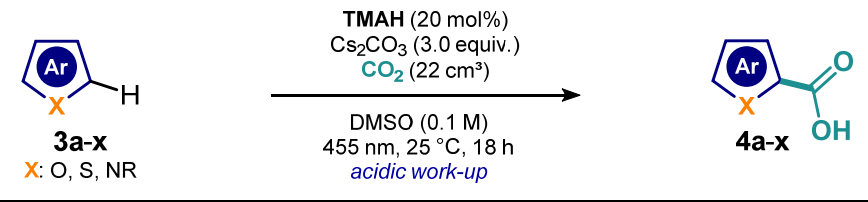<smiles>COC(=O)c1ccc(C(=O)O)s1</smiles>

$4 a, 49 \%$<smiles>O=C(O)c1ccc(-c2ccccc2)s1</smiles>

$4 e, 99 \%$<smiles>N#Cc1ccsc1C(=O)O</smiles>

$4 i, 86 \%$<smiles>O=C(O)c1ccc(-c2cccs2)s1</smiles>
$4 \mathrm{~m}, 53 \%$<smiles>Cc1c(C(=O)O)sc2ccccc12</smiles>

$4 q, 95 \%$

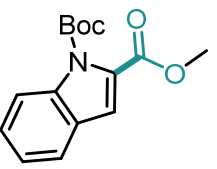

$4 u, 40 \%$<smiles>N#Cc1ccc(C(=O)O)s1</smiles>

4b, $92 \%$<smiles>C[Si](C)(C)c1ccc(C(=O)O)s1</smiles>

4f, $28 \%$<smiles>CC(=O)c1ccsc1C(=O)O</smiles>

$4 \mathrm{j}, 41 \%$<smiles>O=C(O)c1sccc1-c1cccs1</smiles>

$4 n+4 n^{\prime}, 87 \%$

(2.8: 1)<smiles>COC(=O)c1ccc(C(=O)O)o1</smiles>

$4 r, 70 \%$

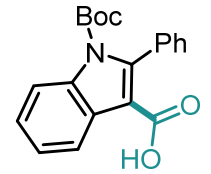

$4 \mathrm{v}, 10 \%$<smiles>CC(=O)c1ccc(C(=O)O)s1</smiles>

4c, $39 \%$<smiles>N#CCc1ccc(C(=O)O)s1</smiles>

$4 \mathrm{~g}, 89 \%$<smiles>COC(=O)c1ccsc1C(=O)O</smiles>

$4 k, 88 \%$<smiles>NC(=O)c1ccc(C(=O)O)s1</smiles>

4d, $91 \%$<smiles>COC(=O)Cc1ccc(C(=O)O)s1</smiles>

4h, $99 \%$<smiles>O=C(O)c1sccc1-c1ccccc1</smiles>

4I, $71 \%$<smiles>O=C(O)c1cc2sccc2s1</smiles>

4o, $48 \%$<smiles>N#Cc1ccc(C(=O)O)o1</smiles>

$4 s, 43 \%$<smiles>O=C(O)c1cc2ccccc2s1</smiles>

$4 p, 97 \%$<smiles>O=C(O)c1cc2ccccc2o1</smiles>

$4 t, 43 \%$

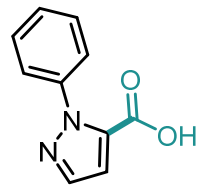

4w, 33\%<smiles>Cc1nc(C#N)sc1C(=O)O</smiles>

$4 x, 53 \%$

Scheme 4. Substrate scope for the carboxylation of 5-membered (hetero)arenes. 
Our procedure allowed for the conversion of methyl thiophene-2-carboxylate to 5-(methoxycarbonyl)thiophene2-carboxylic acid (4a) in one step, providing a much shorter route than by using other reported methods [Scheme 5, A(i)] ${ }^{66}$ Moreover, our method allowed the synthesis of 5-carboxy-2-acetylthiophene (4c), an important building block for the synthesis of the alpha/beta blocker arotinolol, ${ }^{67}$ in one step from 1-(thiophen-2-yl)ethan-1-one (3c). This is significantly shorter than well-established synthetic routes [Scheme 5, A(ii)]. ${ }^{68}$ Remarkably, we also found that 3-substituted thiophenes were exclusively carboxylated in the 2-position (4i-I) which highlights the excellent regioselectivity of this reaction. In comparison, a previous literature report on the lithiation of 3-phenylthiophene (3I) and subsequent carboxylation led to a mixture of $\mathbf{4 I}$ and $\mathbf{4 l}$ ' (Scheme 5, B). ${ }^{69}$ Perfect regioselectivity was also observed for the photocatalyzed carboxylation of 1-phenylpyrazole where only $\mathbf{4 w}$ was obtained. In this case, due to the chelating effect of nitrogen, the use of organometallic reagents leads to product mixtures $(n-\mathrm{BuLi})^{70}$ or to an inverse regioselectivity $(\mathrm{EtMgBr})^{71}$ (Scheme 5, C). This photocatalyzed carboxylation method could also be extended to benzothiophenes (4p-q), furans (4r-s), benzofuran $\mathbf{4 t}$, Boc-protected indoles $(\mathbf{4} \mathbf{u}-\mathbf{v})$ and thiocarbazole 4x. Non-protected $1 H$-indoles however, were carboxylated at the nitrogen atom, as reported in literature. ${ }^{30}$

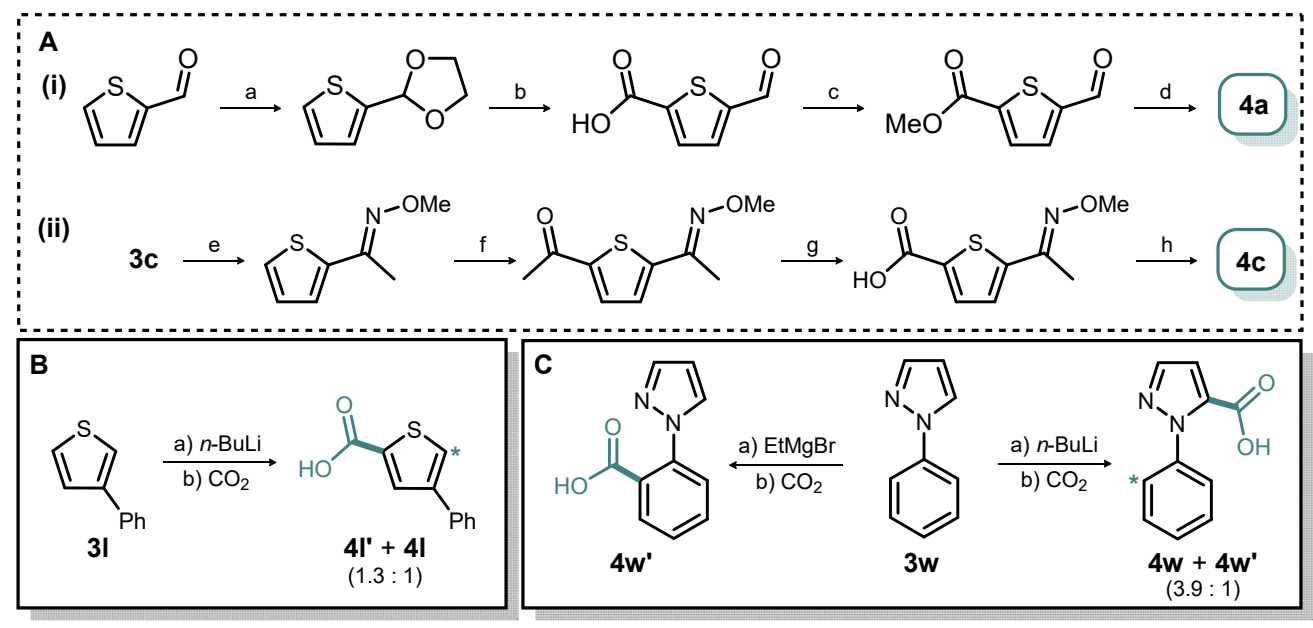

Scheme 5. Commonly applied synthetic routes to obtain products $\mathbf{4 a}$ and $\mathbf{4 c}$ (A). Regioselectivity of organometallic carboxylation $(\mathrm{B}+\mathrm{C})$.

(A) Reported four-step synthesis for compound $4 \mathbf{a}$ (i) ${ }^{66}$ and $4 \mathbf{c}$ (ii) ${ }^{68}$; conditions: (a) ethane-1,2-diol, $\mathrm{Al}_{2} \mathrm{O}_{3}$, $\mathrm{CCl}_{4}, \Delta, 48 \mathrm{~h}$; (b) $n$-BuLi, THF, $-78{ }^{\circ} \mathrm{C}$, then $\mathrm{CO}_{2}$ followed by $\mathrm{H}_{2} \mathrm{SO}_{4}(10 \%)$; (c) $\mathrm{MeI}, \mathrm{Na}_{2} \mathrm{CO}_{3}, \mathrm{DMF}$, $20{ }^{\circ} \mathrm{C}, 48 \mathrm{~h}$; (d) Jones reagent; (e) $\mathrm{MeONH}_{2} \cdot \mathrm{HCl}, \mathrm{Na}_{2} \mathrm{CO}_{3}, \mathrm{H}_{2} \mathrm{O}, \mathrm{MeOH}, \mathrm{AcOH}$ (pH 5), $\Delta, 3 \mathrm{~h}$; (f) $\mathrm{ZnCl}$, $\mathrm{CHCl}_{3}, \mathrm{Ac}_{2} \mathrm{O}, 100{ }^{\circ} \mathrm{C}, 12$ h, r.t., aq. $\mathrm{HCl}(20 \%)(\mathrm{g}) \mathrm{MeOH}$, aq. $\mathrm{NaOCl}(5.5 \%), 70{ }^{\circ} \mathrm{C}, 4$ h, r.t., $\mathrm{HCl}$ conc.; (h) aq. $\mathrm{HCl}, 65^{\circ} \mathrm{C}, 12 \mathrm{~h}$.

(B) $n$-BuLi promoted carboxylation of 31 leads to a mixture of regioisomers

(C) Organometallic methods for carboxylation of 1-phenylpyrazole. Due to the chelating effect of nitrogen, the use of organometallic reagents causes a mixture of regioisomers ( $n$-BuLi) or leads to an inversion of regioselectivity (EtMgBr) yielding benzoic acid $\mathbf{4} \mathbf{w}^{\prime}$ as single product.

Noteworthy, modifying the conditions during the reaction work-up of $\mathbf{4 r}$ allowed the formation of either 2,5furandicarboxylic acid (FDCA) or dimethyl 2,5-furandicarboxylate (DMFDC, see Scheme S4, Supplemental Information). Both are important monomers for the manufacture of polyesters derived from biomass, including 
polyethylene furandicarboxylate (PEF), a potential large-scale substitute for fossil-based polyethylene terephthalate (PET). ${ }^{72,73}$ Lignocellulose is converted into furfural on an industrial scale ${ }^{74}$ and catalytic follow-up procedures have been reported to yield methyl furoate quantitatively. ${ }^{75,76}$ Starting from methyl furan-2-carboxylate 3r, our procedure offers a new one-step synthetic route to form lignocellulose-derived monomers. Remarkably, all examined heterocycles were carboxylated at the five-membered ring in $\alpha$-position (except $\mathbf{4 v}$, where the $\alpha$ position is blocked) to the heteroatom. Contrarily, hydroxybenzothiophene $\mathbf{6 a}$ or condensed heterocycles such as indazoles (6b-c) and pyrazolo[1,5-a]pyridine (6d) showed exclusive selectivity for the six-membered ring (Scheme 6, A). With mild carboxylation conditions in hand, we postulated that this methodology could be applied for the late-stage functionalization of biologically active molecules. To this end, a Boc-protected thiophene analogue of propranolol, a well-established beta blocker bearing a free hydroxyl group in the side chain, was subjected to our reaction conditions. Pleasantly, regioselective carboxylation was successfully achieved to provide 6e, albeit in modest yield.

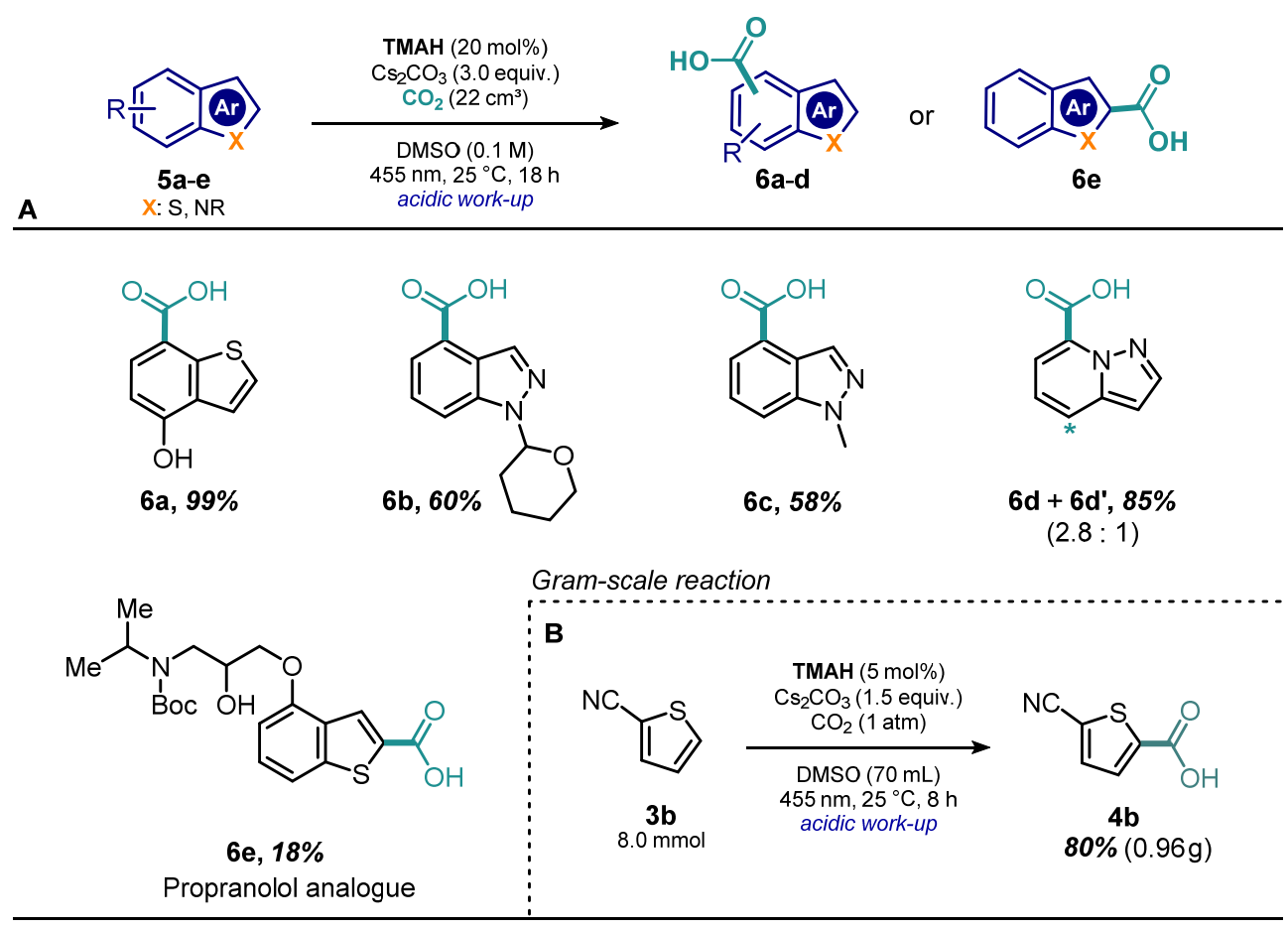

Scheme 6. (A) Substrate scope for the carboxylation of (hetero)arenes on the six-membered ring and example of late-stage functionalization. (B) Reaction conditions for the gram-scale carboxylation of $\mathbf{3 b}$.

To demonstrate the scalability of our reaction, we repeated the synthesis of $\mathbf{4 b}$ on a gram-scale. 2-Cyanothiophene 3b was reacted in a custom-built glass reactor (see Figure S2, Supplemental Information) with a reduced amount of both TMAH ( 5 mol\%) and cesium carbonate (1.5 equiv.) in DMSO (Scheme 6B). Remarkably, as working with $\mathrm{CO}_{2}$ overpressure was not possible with this reaction vessel, a gentle stream of $\mathrm{CO}_{2}$ was sufficient to obtain the product in good yield. 
We then questioned whether our photocatalytic system could be further utilized for the direct carboxylation of other stabilized $\mathrm{sp}^{2}$-hybridized carbon atoms. To this end, we examined styrene derivatives (Scheme 7) and we were delighted to see that under the presented redox-neutral conditions only the corresponding trans-cinnamic acids were obtained. Our protocol thus provides a complementary method to previous net-reductive approaches where excess of sacrificial reductant or electrical current yielded hydrocarboxylated products (cf., Scheme 1). ${ }^{22,48,53}$ Despite the limitation posed by competing polymerization reactions, a variety of vinyl benzenes could be converted into trans-cinnamic acid derivatives 8b-I (Scheme 7), which find applications in the food industry, material science ${ }^{77}$ and cosmetics. ${ }^{78}$ While styrene derivatives bearing electron-donating substituents (7df, 7h) reacted smoothly, the reaction with the electron-poor 4-(trifluoromethyl)styrene resulted in low product yield. 4-Cyanostyrene (7n) or methyl-4-vinylbenzoate (7o) were not suitable substrates under these conditions. As the electron transfer from the excited photocatalyst to an electron-poor styrene is thermodynamically favored, we postulated that electron-withdrawing groups stabilize the negative charge and reduce the nucleophilicity of the corresponding radical anion. When using $\alpha$-methylstyrene, we observed the formation of 3-aryl-3-butenoic acid $\mathbf{8 m}$ in favor of the thermodynamically more stable $\alpha, \beta$-unsaturated acid $\mathbf{8} \mathbf{m}^{\prime}{ }^{38}$

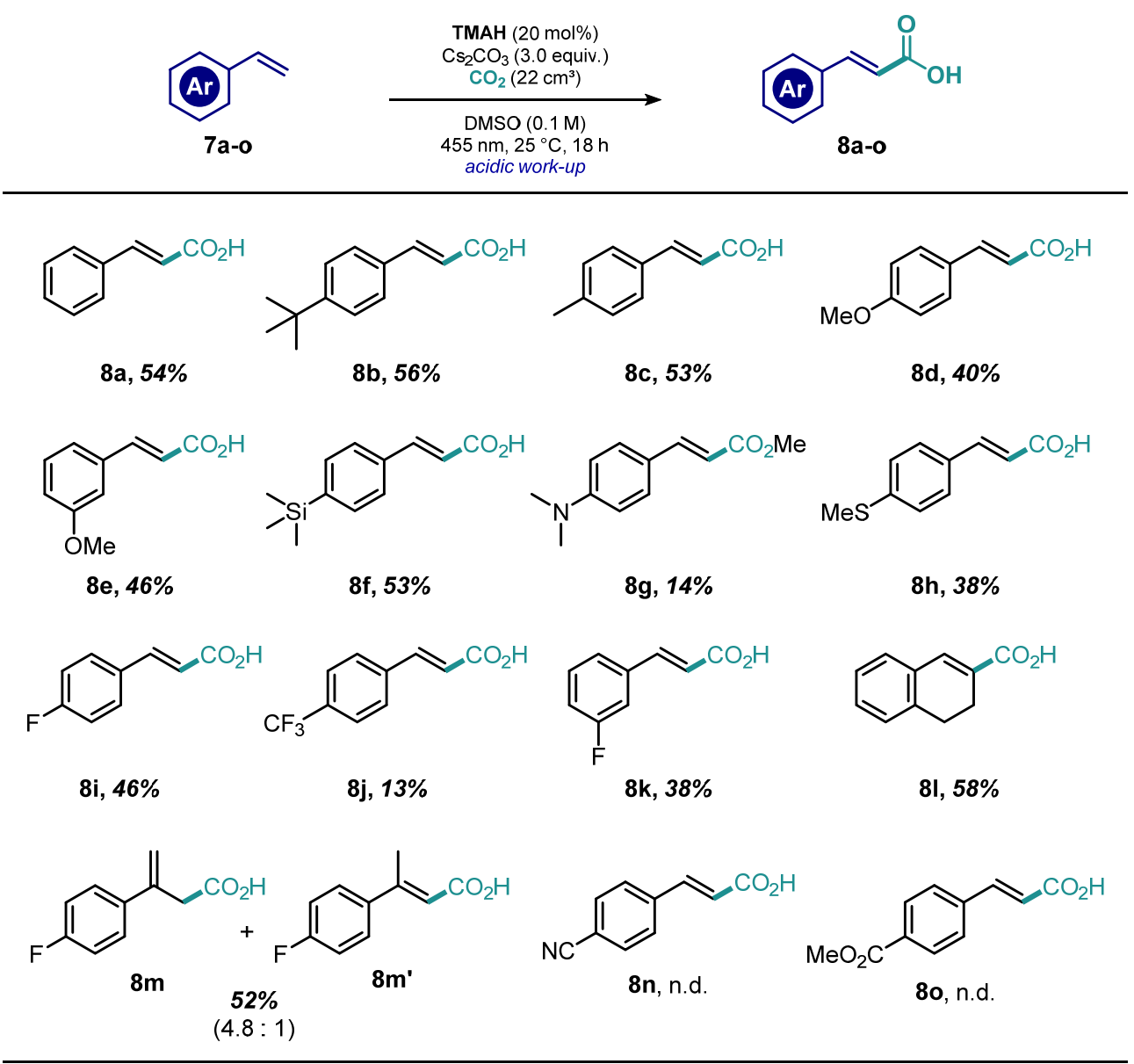

Scheme 7. Substrate scope for the carboxylation of styrene derivatives. 


\section{Mechanistic Insights}

We propose a photoinduced single-electron transfer (SET) from the excited $\mathbf{T M A}^{-*}$ to the substrate as the first step. The excited photocatalyst $\mathbf{T} \mathbf{M} \mathbf{A}^{-*}$ is strongly emissive and its luminescence decay follows first-order kinetics (see Figure S4a-b and Figure S5, Supplemental Information). In presence of chosen (hetero)arenes (cf., Scheme 4) as well as styrenes ( $c f$. ., Scheme 7) we observed a decrease in the luminescence lifetime of TMA ${ }^{-*}$. Based on the obtained data, a Stern-Volmer plot was derived (see Figure S11a-b, Supplemental Information). The luminescence lifetime of TMA ${ }^{-*}$ in a $\mathrm{CO}_{2}$-saturated solution of DMSO remains almost unchanged, indicating that $\mathrm{CO}_{2}$ is not reduced by the photocatalyst. Reduction of $\mathrm{CO}_{2}$ by SET to achieve carbon-bond formation has been reported, but it requires reagents such as $p$-terphenyl radical anion ${ }^{53,79}$. Although a direct reduction of $\mathrm{CO}_{2}$ $(-2.21 \mathrm{~V} \text { vs. SCE in DMF })^{80}$ by $\mathbf{T M A}^{-*}$ is thermodynamically feasible, we assume a kinetic barrier preventing the formation of the bent $\mathrm{CO}_{2}$ radical anion within the excited state lifetime of $\mathbf{T} \mathbf{M} \mathbf{A}^{-*}$. Thus, we ascertained that the productive pathway is dominated by the formation of an aromatic radical anion, which subsequently reacts with $\mathrm{CO}_{2}$ via nucleophilic addition. In order to get further insight into the reaction mechanism, we tested other electrophiles than $\mathrm{CO}_{2}$. We decided to use ketones for this study, as single-electron reduction from the excited photocatalyst to the ketone would give a ketyl radical anion. In sharp contrast to the radical anion of $\mathrm{CO}_{2}$, ketyl radical anions are considered as electron-rich species acting as single-electron reductants rather than forming C-C bonds via radical reactions. ${ }^{81}$ When benzo[b]thiophene (3p. Scheme 8$)$ was reacted with acetone $(\mathbf{9 a})$, the corresponding tertiary alcohol adduct 9 pa was formed in good yield. The luminescence lifetime of $\mathbf{T M A} \mathbf{A}^{-*}$ remains unchanged upon titration with acetone $(-2.84 \mathrm{~V} \text { vs. SCE in DMF })^{82}$ and thus, the formation of a ketyl radical anion is unlikely (Figure S11d, Supplemental Information). Remarkably, similar transformations require very harsh reaction conditions $\left(-78{ }^{\circ} \mathrm{C}\right.$, excess of $n$-BuLi) and are not viable in a one-pot procedure. ${ }^{83}$ Moderate yield of the resulting tertiary alcohol were also obtained using cyclic ketone $\mathbf{9 b}$ and non-conjugated enone $\mathbf{9 c}$ as electrophiles.

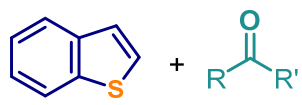

$3 p$

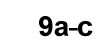
10 equiv.

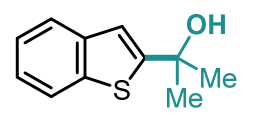

$9 p a, 54 \%$
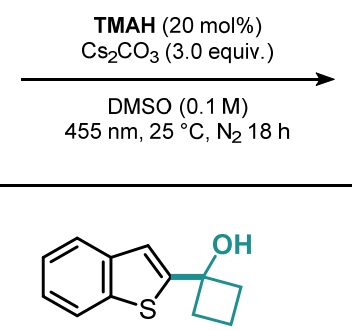

$9 \mathrm{pb}, 30 \%$

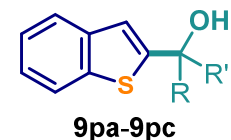

9pa-9pc

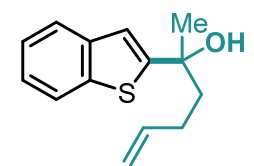

$9 p c, 19 \%$

Scheme 8. Mechanistic investigations: Probing the possibility of other electrophiles as viable candidates for reactivity with aromatic radical anions. 
In addition, we performed deuterium-labeling experiments using $\mathrm{D}_{2} \mathrm{O}$ and ${ }^{t} \mathrm{BuOD}$ respectively. Upon formation of the nucleophilic arene radical anion, we envisioned a fast acid-base reaction followed by reoxidation and deprotonation to yield a mixture of H and D in the substrate (see Scheme S3, Supplemental Information). However, as water in the reaction mixture was found to be detrimental and protic solvents were shown to inhibit the reaction (cf., Table S1, Supplemental Information), only small amounts of incorporated deuterium were detected using benzothiophene 3q (Table S3, Supplemental Information). Based on the aforementioned results we propose the following reaction mechanism for the photocatalytic $\mathrm{C}-\mathrm{H}$ carboxylation of (hetero)arenes (Scheme 9). In the presence of a base, the pre-catalyst TMAH is chemically activated by deprotonation to form an anionic species TMA ${ }^{-}$, indicated by the solution colour change. Upon irradiation with visible light (455 nm) a strongly-reducing excited anion $\mathbf{T} \mathbf{M A}^{-*}$ is formed. The excited state is then quenched by the arene I via SET to afford the radical of the photocatalyst $\mathbf{T M A}^{*}$ and the electron rich radical anion of the arene (II). The Mulliken spin population for each aromatic $\mathrm{sp}^{2}$-hybridized carbon, indicative of reactivity towards $\mathrm{CO}_{2}$, is shown for the benzothiophene radical anion (II). In the bond-forming step $\mathrm{CO}_{2}$ is attacked by II to generate a radical carboxylate III as an intermediate. The catalytic cycle is closed via SET to recapture the active catalyst TMA $^{-}$ followed by re-aromatization of the cationic arene IV upon deprotonation. Despite the weakly oxidizing nature of the photocatalyst, the electron transfer from III to $\mathbf{T M A}^{\bullet}$ may be driven by the stabilization energy gained upon re-aromatization of IV. It remains to be shown if this re-aromatization occurs via electron transfer and subsequent deprotonation as proposed, or via a direct $\mathrm{H}$-atom abstraction by the oxidized photocatalyst.

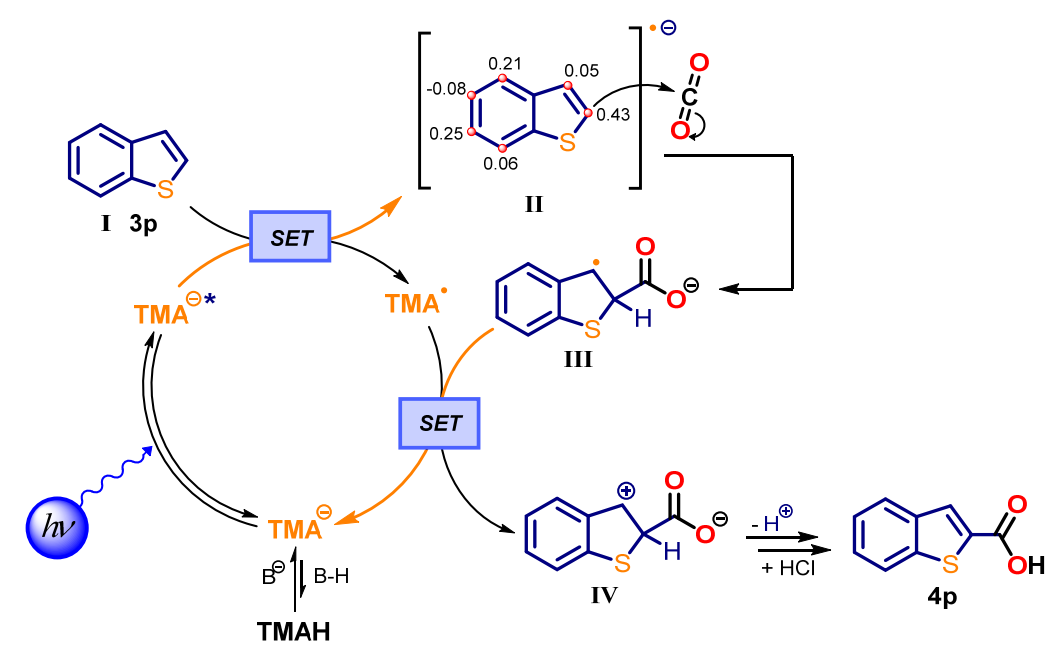

Scheme 9. Proposed mechanism for the $\mathrm{C}-\mathrm{H}$ carboxylation of (hetero)arenes exemplified by the carbxoxylation of benzothiophene.

During the exploration of the substrate scope, we found that several aromatic compounds that quench the excited state of the photocatalyst did not undergo carboxylation (see Figure S11c, Supplemental Information). While some functional groups are understandably not tolerated under our reaction conditions, such as aromatic halides 
(these may undergo fast mesolytic bond-cleavage to form aryl radicals) or highly electrophilic moieties, we were surprised that only certain radical anions were reacting with $\mathrm{CO}_{2}$. In order to determine the required electronic characteristics for reactivity and to improve our insight regarding functional group tolerance, high-throughput screening (HTS) of various arenes containing a large array of functionalities and differing in complexity was carried out (see Figure S9, Supplemental Information). The analysis of the HTS outcome indicates that aldehydes, halides (with the exception of fluorine), aliphatic amines, 6-membered N-heterocycles and nitro groups are not compatible with the reaction conditions. Beyond functional group interference, the applicability of our methodology is related to the arene electron affinity and the nucleophilicity of the resulting radical anion. Arenes may be able to accept an electron with ease, but the radical anion formed may not be nucleophilic enough to add to $\mathrm{CO}_{2}$. Conversely, some aromatic radical anions may be highly nucleophilic, but their formation may be beyond the reductive capabilities of the photocatalyst or a functional group present may be reduced instead. The estimated electron affinities of the arenes, and the Mulliken spin population and charges for the arene radical anions were derived from DFT calculations. The importance of a correct balance of electron affinity of the arene and the nucleophilicity of the aromatic radical anion for a successful reaction is illustrated in Schemes S12a-d (Supplemental Information). The regioselectivity is generally well predicted by comparing the Mulliken spin population for the aromatic carbons in each substrate.

\section{Conclusion}

We have developed a mild, direct, redox-neutral and transition-metal-free insertion of $\mathrm{CO}_{2}$ into nonprefunctionalized $\mathrm{C}\left(\mathrm{sp}^{2}\right)-\mathrm{H}$ bonds, leading to an efficient method for producing valuable aromatic carboxylic acids and trans-cinnamic acids in a single operation. A reaction performed on gram-scale demonstrated the scalability of this carboxylation method, while ketones could be used as alternative electrophiles to $\mathrm{CO}_{2}$ yielding tertiary alcohols. The scope of the reaction can be predicted by DFT-estimated reduction potential of the substrates and nucleophilicity of the intermediate arene radical anions. These findings may open new opportunities for atom-economic and energy efficient use of $\mathrm{CO}_{2}$ as a $\mathrm{C} 1$ building block in the chemical processing of aromatic hydrocarbons, as well as for developing new photocatalytic late-stage functionalizations of drug-like compounds.

\section{Experimental Procedures}

Full experimental procedures are provided in the Supplemental Information

\section{Supplemental Information}

Supplemental Information can be found online. 


\section{Acknowledgments}

We thank Dr. Rudolf Vasold for GC measurements, Ernst Lautenschlager for his help regarding laboratory equipment and Regina Hoheisel for cyclic voltammetry measurements. M.S. thanks Marie-Sofie Dürr \& Andreas Ratzenböck for their assistance. The Physical and Analytical Chemistry team at AstraZeneca is kindly acknowledged for their help with NMR and HRMS analyses of compounds. T.D.S., P.B., M.J.J. and G.B. acknowledge Dr. Malin Lemurell, AstraZeneca and the AstraZeneca PostDoc program for their financial support. This project has received funding from the European Research Council (ERC) under the European Union's Horizon 2020 Research and Innovation Programme (grant agreement No. 741623).

\section{Author Contributions}

M.S. developed the catalytic system, optimized the reaction, isolated the compounds $2 \mathbf{a}-\mathbf{d}, 4 \mathbf{a}-\mathbf{f}, \mathbf{4 i -}-\mathbf{t}, \mathbf{4 v - w}, \mathbf{8 a}-$ m, 9pa-pc, designed and carried out the gram-scale reaction and conducted all experiments to investigate the reaction mechanism. T.D.S. designed and performed the high-throughput-screening and isolated compounds $\mathbf{2 f}$ g, 4g-h, 4u, 4x, 6a-e. F.F. prepared compounds and isolated compound 2e. M.S. and T.D.S. wrote the manuscript and Supplemental Information with input from all of the authors. P.B. conducted the computational studies. M.J.J., G.B. and B.K. supervised the project.

\section{Declaration of Interests}

The authors declare no competing interests. T.D.S., P.B., M.J.J., G.B. are employees and shareholders of AstraZeneca.

\section{References}

1. Hou, H.J.M., Najafpour, M.M., Moore, G.F., and Allakhverdiev, S.I. (2017). Photosynthesis: Structures, mechanisms, and applications (Springer International Publishing).

2. Nitopi, S., Bertheussen, E., Scott, S.B., Liu, X., Engstfeld, A.K., Horch, S., Seger, B., Stephens, I.E.L., Chan, K., Hahn, C., et al. (2019). Progress and Perspectives of Electrochemical $\mathrm{CO}_{2}$ Reduction on Copper in Aqueous Electrolyte. Chem. Rev. 119 , 7610-7672.

3. Küngas, R. (2020). Electrochemical $\mathrm{CO}_{2}$ Reduction for CO Production: Comparison of Low- and High-Temperature Electrolysis Technologies. J. Electrochem. Soc. 167, 044508.

4. Nielsen, D.U., Hu, X.M., Daasbjerg, K., and Skrydstrup, T. (2018). Chemically and electrochemically catalysed conversion of $\mathrm{CO}_{2}$ to $\mathrm{CO}$ with follow-up utilization to value-added chemicals. Nat. Catal. 1, 244-254.

5. Liu, Q., Wu, L., Jackstell, R., and Beller, M. (2015). Using carbon dioxide as a building block in organic synthesis. Nat. Commun. 6, 5933

6. Correa, A., and Martín, R. (2009). Metal-Catalyzed Carboxylation of Organometallic Reagents with Carbon Dioxide. Angew. Chem. Int. Ed. 48, 6201-6204. 
7. Correa, A., and Martín, R. (2009). Palladium-Catalyzed Direct Carboxylation of Aryl Bromides with Carbon Cioxide. J. Am. Chem. Soc. 131, 15974-15975.

8. Tran-Vu, H., and Daugulis, O. (2013). Copper-Catalyzed Carboxylation of Aryl lodides with Carbon Dioxide. ACS Catal. 3 , $2417-2420$.

9. Nogi, K., Tsuji, Y., Terao, J., Xu, T., and Fujihara, T. (2012). Nickel-Catalyzed Carboxylation of Aryl and Vinyl Chlorides Employing Carbon Dioxide. J. Am. Chem. Soc. 134, 9106-9109.

10. Liu, Y., Cornella, J., and Martin, R. (2014). Ni-Catalyzed Carboxylation of Unactivated Primary Alkyl Bromides and Sulfonates with $\mathrm{CO}_{2}$. J. Am. Chem. Soc. 136, 11212-11215.

11. Correa, A., León, T., and Martin, R. (2014). Ni-Catalyzed Carboxylation of $\mathrm{C}\left(\mathrm{sp}^{2}\right)$ - and $\mathrm{C}\left(\mathrm{sp}^{3}\right)-\mathrm{O}$ Bonds with $\mathrm{CO}_{2}$. J. Am. Chem. Soc. 136, 1062-1069.

12. Moragas, T., Cornella, J., and Martin, R. (2014). Ligand-Controlled Regiodivergent Ni-Catalyzed Reductive Carboxylation of Allyl Esters with $\mathrm{CO}_{2}$. J. Am. Chem. Soc. 136, 17702-17705.

13. Mita, T., Higuchi, Y., and Sato, Y. (2015). Highly Regioselective Palladium-Catalyzed Carboxylation of Allylic Alcohols with $\mathrm{CO}_{2}$. Chem. Eur. J. 21, 16391-16394.

14. Moragas, T., Gaydou, M., and Martin, R. (2016). Nickel-Catalyzed Carboxylation of Benzylic C-N Bonds with $\mathrm{CO}_{2}$. Angew. Chem. Int. Ed. 55, 5053-5057.

15. Yanagi, T., Somerville, R.J., Nogi, K., Martin, R., and Yorimitsu, H. (2020). Ni-Catalyzed Carboxylation of C(sp2)-S Bonds with $\mathrm{CO}_{2}$ : Evidence for the Multifaceted Role of Zn. ACS Catal. 10, 2117-2123.

16. Gaydou, M., Moragas, T., Juliá-Hernández, F., and Martin, R. (2017). Site-Selective Catalytic Carboxylation of Unsaturated Hydrocarbons with $\mathrm{CO}_{2}$ and Water. J. Am. Chem. Soc. 139, 12161-12164.

17. Michigami, K., Mita, T., and Sato, Y. (2017). Cobalt-Catalyzed Allylic C(sp3)-H Carboxylation with $\mathrm{CO}_{2}$. J. Am. Chem. Soc. 139, 6094-6097.

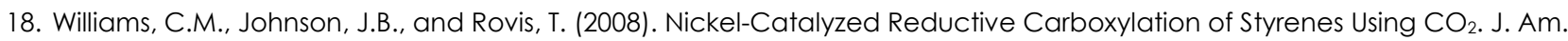
Chem. Soc. 130, 14936-14937.

19. Tortajada, A., Ninokata, R., and Martin, R. (2018). Ni-Catalyzed Site-Selective Dicarboxylation of 1,3-Dienes with $\mathrm{CO}_{2}$. J. Am. Chem. Soc. 140, 2050-2053.

20. Huguet, N., Jevtovikj, I., Gordillo, A., Lejkowski, M.L., Lindner, R., Bru, M., Khalimon, A.Y., Rominger, F., Schunk, S.A., Hofmann, P., et al. (2014). Nickel-Catalyzed Direct Carboxylation of Olefins with $\mathrm{CO}_{2}$ : One-Pot Synthesis of $a, \beta-$ Unsaturated Carboxylic Acid Salts. Chem. Eur. J. 20, 16858-16862.

21. Yang, Y., and Lee, J.W. (2019). Toward ideal carbon dioxide functionalization. Chem. Sci. 10, 3905-3926.

22. Alkayal, A., Tabas, V., Montanaro, S., Wright, I.A., Malkov, A. V., and Buckley, B.R. (2020). Harnessing Applied Potential: Selective $\beta$-Hydrocarboxylation of Substituted Olefins. J. Am. Chem. Soc. 142, 1780-1785.

23. Ang, N.W.J., de Oliveira, J.C.A., and Ackermann, L. (2020). Electro-Reductive Cobalt-Catalyzed Carboxylation: CrossElectrophile Electro-coupling with Atmospheric $\mathrm{CO}_{2}$. Angew. Chem. Int. Ed., doi.org/10.1002/anie.202003218.

24. Ye, J.-H., Miao, M., Huang, H., Yan, S.-S., Yin, Z.-B., Zhou, W.-J., and Yu, D.-G. (2017). Visible-Light-Driven Iron-Promoted Thiocarboxylation of Styrenes and Acrylates with $\mathrm{CO}_{2}$. Angew. Chem. Int. Ed. 56, 15416-15420.

25. Wang, H., Zhou, C., Li, G., Wang, H., Gao, Y., Zhou, C., and Li, G. (2020). Visible-Light-Driven Reductive Carboarylation of Styrenes with $\mathrm{CO}_{2}$ and Aryl Halides. J. Am. Chem. Soc. 142, 8122-8129.

26. Yatham, V.R., Shen, Y., and Martin, R. (2017). Catalytic Intermolecular Dicarbofunctionalization of Styrenes with $\mathrm{CO}_{2}$ and Radical Precursors. Angew. Chem. Int. Ed. 56, 10915-10919.

27. Hou, J., Ee, A., Cao, H., Ong, H.-W., Xu, J.-H., and Wu, J. (2018). Visible-Light-Mediated Metal-Free Difunctionalization of Alkenes with $\mathrm{CO}_{2}$ and Silanes or $\mathrm{C}\left(\mathrm{sp}^{3}\right)-\mathrm{H}$ Alkanes. Angew. Chem. Int. Ed. 57, 17220-17224.

28. Fu, Q., Bo, Z.Y., Ye, J.H., Ju, T., Huang, H., Liao, L.L., and YU, D.G. (2019). Transition metal-free phosphonocarboxylation of alkenes with carbon dioxide via visible-light photoredox catalysis. Nat. Commun. 10, 1-9.

29. Luo, J., Preciado, S., Xie, P., and Larrosa, I. (2016). Carboxylation of Phenols with $\mathrm{CO}_{2}$ at Atmospheric Pressure. Chem. Eur. J. 22, 6798-6802.

30. Yoo, W.J., Capdevila, M.G., Du, X., and Kobayashi, S. (2012). Base-Mediated Carboxylation of Unprotected Indole 
Derivatives with Carbon Dioxide. Org. Lett. 14, 5326-5329.

31. Shigeno, M., Hanasaka, K., Sasaki, K., Nozawa-Kumada, K., and Kondo, Y. (2019). Direct Carboxylation of Electron-Rich Heteroarenes Promoted by LiO-tBu with CsF and [18]Crown-6. Chem. Eur. J. 25, 3235-3239.

32. Suzuki, Y., Hattori, T., Okuzawa, T., and Miyano, S. (2002). Lewis Acid-Mediated Carboxylation of Fused Aromatic Compounds with Carbon Dioxide. Chem. Lett., 102-103.

33. Nemoto, K., Yoshida, H., Suzuki, Y., Morohashi, N., and Hattori, T. (2006). Beneficial Effect of TMSCl in the Lewis Acidmediated Carboxylation of Aromatic Compounds with Carbon Dioxide. Chem. Lett. 35, 820-821.

34. Nemoto, K., Yoshida, H., Egusa, N., Morohashi, N., and Hattori, T. (2010). Direct Carboxylation of Arenes and Halobenzenes with $\mathrm{CO}_{2}$ by the Combined Use of $\mathrm{AlBr}_{3}$ and $\mathrm{R}_{3} \mathrm{SiCl}$. J. Org. Chem. 75, 7855-7862.

35. Olah, G.A., Török, B., Joschek, J.P., Bucsi, I., Esteves, P.M., Rasul, G., and Prakash, G.K.S. (2002). Efficient Chemoselective Carboxylation of Aromatics to Arylcarboxylic Acids with a Superelectrophilically Activated Carbon Dioxide- $\mathrm{Al}_{2} \mathrm{Cl}_{6} / \mathrm{Al}$ System. J. Am. Chem. Soc. 124, 11379-11391.

36. Nemoto, K., Onozawa, S., Egusa, N., Morohashi, N., and Hattori, T. (2009). Carboxylation of indoles and pyrroles with $\mathrm{CO}_{2}$ in the presence of dialkylaluminum halides. Tetrahedron Lett. 50, 4512-4514.

37. Nemoto, K., Onozawa, S., Konno, M., Morohashi, N., and Hattori, T. (2012). Direct Carboxylation of Thiophenes and Benzothiophenes with the Aid of EłAICl 2 . Bull. Chem. Soc. Jpn. 85, 369-371.

38. Tanaka, S., Watanabe, K., Tanaka, Y., and Hattori, T. (2016). E†AlCl $2 / 2,6$-Disubstituted Pyridine-Mediated Carboxylation of Alkenes with Carbon Dioxide. Org. Lett. 18, 2576-2579.

39. Boogaerts, I.I.F., Fortman, G.C., Furst, M.R.L., Cazin, C.S.J., and Nolan, S.P. (2010). Carboxylation of N-H/C-H Bonds Using Nheterocyclic Carbene Copper(I) Complexes. Angew. Chem. Int. Ed. 49, 8674-8677.

40. Zhang, L., Cheng, J., Ohishi, T., and Hou, Z. (2010). Copper-Catalyzed Direct Carboxylation of C-H Bonds with Carbon Dioxide. Angew. Chem. Int. Ed. 49, 8670-8673.

41. Suga, T., Mizuno, H., Takaya, J., and Iwasawa, N. (2014). Direct carboxylation of simple arenes with $\mathrm{CO}_{2}$ through a rhodium-catalyzed C-H bond activation. Chem. Commun. 50, 14360-14363.

42. Hong, J., Li, M., Zhang, J., Sun, B., and Mo, F. (2019). C-H Bond Carboxylation with Carbon Dioxide. ChemSusChem 12, 639.

43. Banerjee, A., Dick, G.R., Yoshino, T., and Kanan, M.W. (2016). Carbon dioxide utilization via carbonate-promoted C-H carboxylation. Nature 531, 215-219.

44. Kudo, K., Shima, M., Kume, Y., Ikoma, F., Mori, S., and Sugita, N. (1995). Carboxylation of Cesium 2-Naphthoate in the Alkali Metal Molten Salts of Carbonate and Formate with $\mathrm{CO}_{2}$ under High Pressure. J. Jpn. Petrol. Inst. 38, 40-47.

45. Shimomaki, K., Murata, K., Martin, R., and Iwasawa, N. (2017). Visible-Light-Driven Carboxylation of Aryl Halides by the Combined Use of Palladium and Photoredox Catalysts. J. Am. Chem. Soc. 139, 9467-9470.

46. Meng, Q.-Y., Wang, S., and König, B. (2017). Carboxylation of Aromatic and Aliphatic Bromides and Triflates with $\mathrm{CO}_{2}$ by Dual Visible-Light-Nickel Catalysis. Angew. Chem. Int. Ed. 56, 13426-13430.

47. Hou, J., Ee, A., Feng, W., XU, J.H., Zhao, Y., and WU, J. (2018). Visible-Light-Driven alkyne hydro-/carbocarboxylation using $\mathrm{CO}_{2}$ via iridium/cobalt dual catalysis for divergent heterocycle synthesis. J. Am. Chem. Soc. 140, 5257-5263.

48. Meng, Q.Y., Wang, S., Huff, G.S., and König, B. (2018). Ligand-Controlled Regioselective Hydrocarboxylation of Styrenes with $\mathrm{CO}_{2}$ by Combining Visible Light and Nickel Catalysis. J. Am. Chem. Soc. 140, 3198-3201.

49. Murata, K., Numasawa, N., Shimomaki, K., Takaya, J., and Iwasawa, N. (2017). Construction of a visible light-driven hydrocarboxylation cycle of alkenes by the combined use of Rh(I) and photoredox catalysts. Chem. Commun. 53, 30983101 .

50. Meng, Q.-Y., Schirmer, T.E., Berger, A.L., Donabaver, K., and König, B. (2019). Photocarboxylation of Benzylic C-H Bonds. J. Am. Chem. Soc. 141, 11393-11397.

51. Tagaya, H., Onuki, M., Tomioka, Y., Wada, Y., Karasu, M., and Chiba, K. (1990). Photocarboxylation of Naphthalene in the Presence of Carbon Dioxide and an Electron Donor. Bull. Chem. Soc. Jpn. 63, 3233-3237.

52. Minabe, M., Isozumi, K., Kawai, K., and Yoshida, M. (1988). An Observation on Carboxylation of 4HCyclopenta[def]phenanthrene. Bull. Chem. Soc. Jpn. 61, 2063-2066. 
53. Seo, H., Liv, A., and Jamison, T.F. (2017). Direct $\beta$-Selective Hydrocarboxylation of Styrenes with $\mathrm{CO}_{2}$ Enabled by Continuous Flow Photoredox Catalysis. J. Am. Chem. Soc. 139, 13969-13972.

54. Ishida, N., Masuda, Y., Uemoto, S., and Murakami, M. (2016). A Light/Ketone/Copper System for Carboxylation of Allylic $\mathrm{C}-\mathrm{H}$ Bonds of Alkenes with $\mathrm{CO}_{2}$. Chem. Eur. J. 22, 6524-6527.

55. Ishida, N., Masuda, Y., Imamura, Y., Yamazaki, K., and Murakami, M. (2020). Carboxylation of Benzylic and Aliphatic C-H bonds with $\mathrm{CO}_{2}$ Induced by Light/Ketone/Nickel. J. Am. Chem. Soc. 141, 19611-19615.

56. Schmalzbaver, M., Ghosh, I., and König, B. (2019). Utilising excited state organic anions for photoredox catalysis: Activation of (hetero)aryl chlorides by visible light-absorbing 9-anthrolate anions. Faraday Discuss. 215, 364-378.

57. Mutule, I., and Suna, E. (2005). Arylzinc species by microwave assisted Grignard formation-transmetallation sequence: Application in the Negishi coupling. Tetrahedron 61, 11168-11176.

58. Hussey, A.S. (1951). The Carbonation of Grignard Reagent Solutions. J. Am. Chem. Soc. 73, 1364-1365.

59. Nagaki, A., Takahashi, Y., and Yoshida, J. (2014). Extremely Fast Gas/Liquid Reactions in Flow Microreactors: Carboxylation of Short-Lived Organolithiums. Chem. Eur. J. 20, 7931-7934.

60. Polyzos, A., O'Brien, M., Petersen, T.P., Baxendale, I.R., and Ley, S. V. (2011). The Continuous-Flow Synthesis of Carboxylic Acids using $\mathrm{CO}_{2}$ in a Tube-In-Tube Gas Permeable Membrane Reactor. Angew. Chem. Int. Ed. 50, 1190-1193.

61. Holy, N.L. (1974). Reactions of the Radical Anions and Dianions of Aromatic Hydrocarbons. Chem. Rev. 74, $243-277$.

62. Schlenk, W., and Bergmann, E. (1928). Forschungen auf dem Gebiete der alkaliorganischen Verbindungen. I. Über Produkte der Addition von Alkalimetal an mehrfache Kohlenstoff-Kohlenstoff-Bindungen. Justus Liebigs Ann. Chem. 463, 197.

63. Walker, J.F., and Scott, N.D. (1938). Sodium Naphthalene. II. Preparation and Properties of Dihydronaphthalene Dicarboxylic Acids. J. Am. Chem. Soc. 60, 951-955.

64. Gennaro, A., Isse, A.A., and Vianello, E. (1990). Solubility and electrochemical determination of $\mathrm{CO}_{2}$ in some dipolar aprotic solvents. J. Electroanal. Chem. 289, 203-215.

65. Montalti, M., Credi, A., Prodi, L., and Gandolfi, M.T. (2006). Handbook of Photochemisty 3rd ed. (CRC Press).

66. Mahboobi, S., Dove, S., Sellmer, A., Winkler, M., Eichhorn, E., Pongratz, H., Ciossek, T., Baer, T., Maier, T., and Beckers, T. (2009). Design of Chimeric Histone Deacetylase- and Tyrosine Kinase-Inhibitors: A Series of Imatinib Hybrides as Potent Inhibitors of Wild-Type and Mutant BCR-ABL, PDGF-Rß, and histone deacetylases. J. Med. Chem. 52, 2265-2279.

67. Hara, Y., Sato, E., Miyagishi, A., Aisaka, A., and Hibino, T. (1978). Synthesis and $\beta$-Adrenergic Blocking Action of a New Thiazolylthiopropanolamine Derivative. J. Pharm. Sci. 67, 1334-1335.

68. Liu, H., Tang, H., Yang, D., and Ji, Q. (2011). Synthesis of Arotinolol Hydrochloride. Chinese J. Pharm. 42, 641-644.

69. Gschwend, H.W., and Rodriguez, H.R. (1979). Heteroatom-Facilitated Lithiations. In Organic Reactions (John Wiley \& Sons, Inc.), pp. 1-360.

70. Alley, P.W., and Shirley, D.A. (1958). The Metalation of 1-Phenyl- and 1-Methylpyrazole with n-Butyllithium. J. Am. Chem. Soc. $80,6271-6274$.

71. Marxer, A., and Siegrist, M. (1974). Über die Umsetzung von 1-Phenylpyrazol mit Äthylmagnesiumbromid. 8. Mitteilung über Grignard-Reaktionen. Helv. Chim. Acta 57, 1988-2000.

72. Banella, M.B., Bonucci, J., Vannini, M., Marchese, P., Lorenzetti, C., and Celli, A. (2019). Insights into the Synthesis of Poly (ethylene 2,5-Furandicarboxylate) from 2,5-Furandicarboxylic Acid: Steps toward Environmental and Food Safety Excellence in Packaging Applications. Ind. Eng. Chem. Res. 58, 8955-8962.

73. Sousa, A.F., Vilela, C., Fonseca, A.C., Matos, M., Freire, C.S.R., Gruter, G.J.M., Coelho, J.F.J., and Silvestre, A.J.D. (2015). Biobased polyesters and other polymers from 2,5-furandicarboxylic acid: A tribute to furan excellency. Polym. Chem. 6 , 5961-5983.

74. Lange, J.-P., van der Heide, E., van Buijtenen, J., and Price, R. (2012). Furfural-A Promising Platform for Lignocellulosic Biofuels. ChemsusChem 5, 150-166.

75. Cho, A., Byun, S., Cho, J.H., and Kim, B.M. (2019). AuPd- $\mathrm{Fe}_{3} \mathrm{O}_{4}$ Nanoparticle-Catalyzed Synthesis of Furan-2,5dimethylcarboxylate from 5-Hydroxymethylfurfural under Mild Conditions. ChemSusChem 12, 2310-2317.

76. Zhou, H., Hong, S., Zhang, H., Chen, Y., XU, H., Wang, X., Jiang, Z., Chen, S., and Liu, Y. (2019). Toward biomass-based 
single-atom catalysts and plastics: Highly active single-atom Co on $\mathrm{N}$-doped carbon for oxidative esterification of primary alcohols. Appl. Catal. B-Environ. 256, 117767.

77. Fonseca, A.C., Lima, M.S., Sousa, A.F., Silvestre, A.J., Coelho, J.F.J., and Serra, A.C. (2019). Cinnamic acid derivatives as promising building blocks for advanced polymers: Synthesis, properties and applications. Polym. Chem. 10, $1696-1723$.

78. Gunia-Krzyżak, A., Słoczyńska, K., Popiół, J., Koczurkiewicz, P., Marona, H., and Pękala, E. (2018). Cinnamic acid derivatives in cosmetics: current use and future prospects. Int. J. Cosmet. Sci. 40, 356-366.

79. Seo, H., Katcher, M.H., and Jamison, T.F. (2017). Photoredox activation of carbon dioxide for amino acid synthesis in continuous flow. Nat. Chem. 9, 453-456.

80. Lamy, E., Nadjo, L., and Saveant, J.M. (1977). Standard potential and kinetic parameters of the electrochemical reduction of carbon dioxide in dimethylformamide. J. Electroanal. Chem. 78, 403-407.

81. Xia, Q., Dong, J., Song, H., and Wang, Q. (2018). Visible-Light Photocatalysis of the Ketyl Radical Coupling Reaction. Chem. Eur. J. 25, 2949-2961.

82. Fuchigami, T., Inagi, S., and Atobe, M. eds. (2014). Appendix B. In Fundamentals and Applications of Organic Electrochemistry (John Wiley \& Sons Ltd), pp. 217-222.

83. Raghu, M., Grover, J., and Ramasastry, S.S. V. (2016). Cyclopenta[b]annulation of Heteroarenes by Organocatalytic $\mathrm{Y}^{\prime}\left[\mathrm{C}\left(\mathrm{sp}^{3}\right)-\mathrm{H}\right]$ Functionalization of Ynones. Chem. Eur. J. 22, 18316-18321. 